\title{
A FORMAÇÃO SUPERIOR EM GASTRONOMIA E A REALIDADE DO MERCADO DE TRABALHO NO ESTADO DE SÃO PAULO: PERCEPÇÕES DE COORDENADORES E EMPREGADORES ${ }^{1}$
}

\author{
HIGHER EDUCATION IN GASTRONOMY AND THE REALITY \\ OF THE JOB MARKET IN THE STATE OF SÃO PAULO: \\ PERCEPTIONS OF COORDINATORS AND EMPLOYERS
}

\section{FORMACIÓN SUPERIOR EN GASTRONOMÍA Y LA REALIDAD DEL MERCADO DE TRABAJO EN EL ESTADO DE SÃO PAULO: PERCEPCIONES DE COORDINADORES Y EMPLEADORES}

\author{
MARIA HENRIQUETA S. G. GIMENES-MINASSE \\ Doutora em História pela Universidade Federal do Paraná - UFPR \\ Universidade Anhembi Morumbi \\ mariegimenes@gmail.com \\ http://orcid.org/0000-0002-4952-808X
}

DATA DE SUBMISSÃO: 02/04/2018 - DATA DE ACEITE: 04/09/2018

RESUMO: Este artigo discute a formação superior em Gastronomia no Estado de São Paulo e sua relação com o mercado, a partir das percepções de coordenadores de cursos e de profissionais do mercado. É uma pesquisa qualitativa, baseada em pesquisa bibliográfica, documental e de campo (survey com 20 coordenadores de curso e 152 profissionais do mercado respondentes). Verificou-se que: a) os dois grupos de respondentes valorizam a graduação em Gastronomia como forma de formação de profissionais; b) os principais diferenciais oferecidos pelos cursos são os conteúdos relacionados à categoria formação ampla e à categoria formação técnica; c) os grupos de respondentes concordam de forma significativa em relação às habilidades e às competências fundamentais para garantir a empregabilidade na área; d) os grupos de respondentes percebem que a inserção dos egressos no mercado do trabalho tem ocorrido, mas que o nível de remuneração e as expectativas dos egressos em relação às tarefas que serão desempenhadas e à ascensão profissional dificultam a permanência no mercado de trabalho; e) os grupos de respondentes concordam sobre a necessidade de ajustes para melhorar a aproximação entre a formação e o mercado de trabalho, e permitir que o aluno conheça as reais condições de uma cozinha profissional.

PALAVRAS-CHAVE: Hospitalidade. Gastronomia. Formação superior. Estado de São Paulo (Brasil).

ABSTRACT: This article discusses the relationship between higher education in Gastronomy in the State of São Paulo, and the job market, based on perceptions of course coordinators and market professionals. It is a qualitative study, based on bibliographic, documentary and field research (a questionnaire, which was completed by 20 course coordinators and 152

1 A realização desta pesquisa contou com apoio e recursos financeiros do CNPq (Coordenação Nacional de Desenvolvimento Científico e Tecnológico) obtidos por meio do Projeto/Processo 471225/2014-2.

Licença CC BY: Artigo distribuído sob os termos e Commons, permite uso e distribuição irrestrita em qualquer meio desde que o autor credite a fonte original. 
professionals working in the market). It was found that: a) both groups of respondents value graduation in Gastronomy as a form of professional training; b) the main differentials offered by the courses are the contents related to the category of extensive training and technical training; c) both groups of respondents agree significantly on the skills and competencies that are essential to ensure employability in the area; d) both groups of respondents perceive that graduates are managing to find jobs in the market, but that the level of pay, the graduates' expectations of the types of tasks they need to carry out, and their desire for professional growth, are causing them to leave and look for other positions; (e) both groups of respondents agree that changes are needed to bring the training closer to what is required for the job market, and give the student a better understand of what working in a professional kitchen involves.

KEYWORDS: Hospitality. Gastronomy. Higher Education. State of São Paulo (Brazil).

RESUMEN: Este artículo discute la formación superior en Gastronomía en el Estado de São Paulo y su relación con la realidad del mercado, a partir de las percepciones de coordinadores de cursos y de representantes del mercado. Es una investigación cualitativa, basada en la investigación bibliográfica, documental y de campo (encuesta con 20 coordinadores de curso y 152 profesionales del mercado). Con un cuestionario semiabierto. Se verificó: a) que los dos grupos de encuestados valoran la graduación en Gastronomía como estrategia de formación; b) los principales diferenciales ofrecidos por los cursos son los contenidos relacionados con la categoría de formación amplia y la categoría de formación técnica; c) concuerdan de forma significativa en relación a la indicación de las habilidades y competencias fundamentales para garantizar la empleabilidad en el área; d) perciben que la inserción de los egresados en el mercado del trabajo ha ocurrido, pero que aspectos relacionados con la remuneración y las expectativas de los egresados en relación a las tareas que se desempeñan y el ascenso profesional dificultan la permanencia en el mercado de trabajo; e) concuerdan sobre la necesidad de ajustes necesarios para mejorar la aproximación de la formación con el mercado de trabajo, en el sentido de permitir que el alumno conozca las reales condiciones de actuación en una cocina profesional.

PALABRAS-CLAVE: Hospitalidad. Gastronomía. Formación superior. Estado de São Paulo (Brasil).

\section{INTRODUÇÃO}

A Gastronomia e os serviços a ela relacionados, no contexto do turismo, podem integrar tanto a oferta técnica quanto a oferta diferencial de um destino. Autores como Richards (2002), Schlüter (2006) e Croce e Perri (2010) apontam as práticas alimentares como elementos estratégicos para a diferenciação de destinos, na medida em que consistem em relevantes expressões da identidade cultural de uma localidade. Neste contexto, profissionais de cozinha capacitados são fundamentais para reproduzir receitas tradicionais ou surpreender comensais com pratos inovadores. Nos grandes centros urbanos, onde o hábito de comer fora não é restrito aos visitantes e foi incorporado por uma grande parcela da população nas últimas décadas, a demanda por estes profissionais é bastante significativa.

A expansão dos serviços de alimentação fora do lar, associada à valorização midiática do universo da Gastronomia, incentivou muitos brasileiros a buscar uma carreira a partir de uma formação especializada. E como observam Toledo e Bergamo (2011, p.82), este "novo ambiente faz emergir nas organizações a necessidade de um profissional mais qualificado, mais flexível e multifuncional, indispensável para o sucesso e, talvez, para a própria sobrevivência das organizações contemporâneas".

Embora os cursos técnicos e de curta duração para cozinha e salão tenham sido introduzidos no Brasil na década de 1950 pelo Serviço Nacional de Aprendizagem Comercial 
(SENAC), os cursos superiores surgiram apenas em $1999^{2}$ (Rubim; Rejowski, 2013). Desde então tiveram uma expansão expressiva: no Estado de São Paulo, por exemplo, entre 1999 e 2017 foram criados ao todo 47 cursos. Este crescimento se deu principalmente por meio da graduação tecnológica. Segundo Anjos et al. (2017), dos 151 cursos superiores em Gastronomia existentes em 2017 no país, 142 pertenciam a esta modalidade.

Os cursos tecnológicos são direcionados às necessidades do mercado de trabalho e respeitam os parâmetros legais da Lei de Diretrizes e Bases da Educação nº 9.394 publicada em 1996 (LDB 1996). Possuem duração menor em relação aos cursos de bacharelado, ênfase no caráter prático e são regidos pelo Catálogo Nacional dos Cursos Superiores de Tecnologia (CNCST), cuja última edição descreve assim o perfil do tecnólogo em Gastronomia:

Concebe, planeja, gerencia e operacionaliza produções culinárias nas diferentes fases dos serviços de alimentação. Cria preparações culinárias e valoriza a ciência dos ingredientes. Diferencia e coordena técnicas culinárias. Planeja, controla e avalia custos. Coordena e gerencia pessoas de sua equipe. Valida a segurança alimentar. Planeja, elabora e organiza projetos de fluxo de montagem de cozinha. Identifica utensílios, equipamentos e matériaprima em restaurantes e estabelecimentos alimentícios. Articula e coordena empreendimentos e negócios gastronômicos. Identifica novas perspectivas do mercado alimentício. Vistoria, avalia e emite parecer técnico em sua área de formação. (MEC, 2016, p. 152).

Os egressos, denominados gastrólogos ${ }^{3}$ ou gastrônomos ${ }^{4}$, devem receber uma formação ampla e complexa, abrangendo habilidades de caráter operacional, criativo e gerencial, com o domínio de técnicas culinárias e de conteúdos associados ao planejamento de operações da cozinha e de gestão de negócios gastronômicos. E, segundo Toledo e Bergamo (2011), como o mercado gastronômico está em mutação contínua, os cursos de formação superior na área enfrentam desafios constantemente. Diante deste contexto, temse como objetivo discutir a formação superior em Gastronomia no Estado de São Paulo e sua relação com a realidade do mercado de trabalho a partir das percepções de coordenadores de cursos superiores em Gastronomia e de representantes do mercado de trabalho, atuando na condição de empregadores.

Este artigo está organizado nas seguintes partes: fundamentação teórica, procedimentos metodológicos, apresentação e análise dos resultados (dividida em visão dos coordenadores, visão dos profissionais de mercado e análise geral, que compara os principais pontos a partir do ponto de vista dos dois grupos abordados) e considerações finais. Entre os principais resultados, verificou-se que os dois grupos de respondentes valorizam a graduação em Gastronomia como forma de formação de profissionais; concordam de forma significativa em

2 Em fevereiro de 1999 teve início o Curso de Turismo (modalidade bacharelado) com Habilitação em Gastronomia na Universidade do Sul de Santa Catarina em Florianópolis (SC); em março o Curso Superior de Formação Específica em Gastronomia (modalidade sequencial) na Universidade Anhembi Morumbi na cidade de São Paulo (SP); e em julho o Curso de Gastronomia (modalidade sequencial e Graduação) na Universidade do Vale do Itajaí em Itajaí (SC) (Miyazaki, 2006).

3 A CBO 2002 (Classificação Brasileira de Ocupações) prevê a ocupação de tecnólogo em Gastronomia (ou gastrólogo), descrevendo os profissionais como aqueles que "criam e elaboram pratos e cardápio, atuando direta e indiretamente na preparação dos alimentos. Gerenciam a brigada de cozinha e planejam as rotinas de trabalho. Podem gerenciar, ainda, os estoques e atuar na capacitação de funcionários" (MTE, 2010).

4 Termo utilizado para caracterizar tanto os profissionais da área de Gastronomia quanto os egressos dos cursos superiores de Gastronomia. Não possui uma definição oficial, como o termo 'gastrólogo', embora seja eventualmente utilizado como seu sinônimo. 
relação às habilidades e às competências fundamentais para garantir a empregabilidade na área; percebem que a inserção dos egressos no mercado do trabalho tem ocorrido, apontando dificuldades relacionadas à permanência neste mercado; e concordam sobre a necessidade de ajustes para melhorar a aproximação entre a formação e o mercado de trabalho, permitindo que o aluno conheça as reais condições de uma cozinha profissional.

\section{FUNDAMENTAÇÃO TEÓRICA}

A formação superior em Gastronomia no Brasil tem sido tema de pesquisas com diferentes abordagens, que se concentram: na formação de professores (Miyazaki, 2006; Rampim, 2010), na formação dos profissionais (Schawn, 2009; Lima, 2010), nas expectativas dos alunos (Werdini, 2013), na estruturação curricular (Krause, 2001; Carneiro, 2008; Domingues, 2008; Abreu, 2013) e na análise geral da evolução desta área de formação (Rubim; Rejowski, 2013; Anjos et al., 2017).

Estas pesquisas muitas vezes abordam um único aspecto da formação e são desenvolvidas a partir de amostras reduzidas, que terminam por ouvir apenas um grupo específico de sujeitos (em sua maioria, ou professores ou alunos). Foram desenvolvidas, em sua maioria, como dissertações de mestrado, trabalhos que, segundo Gimenes-Minasse (2015, p.171), parecem "atender duas necessidades criadas pela expansão do ensino superior em Gastronomia: a de compreensão desta nova realidade e também a demanda por profissionais pós-graduados pelas instituições de ensino superior que decidiram investir na área".

Do ponto de vista da literatura internacional, pode-se identificar os trabalhos de Santich (2004) que trata do ensino e da pesquisa em Gastronomia no contexto da hospitalidade; o de Hertzman e Ackerman (2011), o qual aborda a avaliação da qualidade de programas de formação em gastronomia; o de Hegarty (2011), o qual enfoca a importância da reflexão crítica na formação dos alunos de gastronomia; e o de Mitchell et al. (2013), o qual trata do uso de metodologias inovadoras no ensino de Gastronomia.

Em relação à realidade profissional, Werdini (2013) observa que, durante décadas, boa parte da mão de obra empregada na área, especialmente na cozinha, foi formada por profissionais sem conhecimento técnico. Esse modelo, em que o iniciante aprende diretamente com um mestre no local de trabalho, tem origem europeia e foi muito influente em todo o ocidente, inclusive nos Estados Unidos, onde o primeiro curso superior em Gastronomia foi iniciado em 1946 (Hertzman; Ackerman, 2010). Contudo, o aumento da competitividade e do refinamento do setor tem resultado na substituição dos cozinheiros de formação empírica por aqueles com formação superior, o que tem criado novos hábitos e uma nova linguagem no cotidiano da cozinha comercial brasileira (Werdini, 2013).

Tendo em vista a complexidade deste mercado, Krause (2001, p. 18) defende uma responsabilidade em parceria "das entidades de classe e instituições de educação profissional ou superior, no que se refere à identificação do perfil adequado às exigências de um mercado globalizado até à identificação das possibilidades de intervenção mediante o atendimento adequado às necessidades existentes". Assim, a proximidade entre as instituições de ensino e representantes do mercado é fundamental para a formação de profissionais atualizados que possam contribuir para a melhoria dos produtos e dos serviços deste setor, nos mais diferentes cargos de atuação. 
Belcufine (2011) destaca, como funções que podem ser desempenhadas por um gastrônomo, cargos como maître, sommelier, barista, barman, gestor, comprador, personal chef, magistério, food designer, dentre outros. Schawn (2009) observa que as atividades da cozinha são exercidas por profissionais com diferentes competências e responsabilidades, organizados em uma hierarquia cujo topo é ocupado pela figura do chef, o responsável por comandar uma equipe que exerce atividades em diferentes praças (setores). Porém se nota, a partir da análise das divulgações on-line dos cursos do Estado de São Paulo, que esta amplitude de possibilidades é divulgada, mas que o foco da formação oferecida é o chef de cozinha.

Atala e Dória (2008), observando a complexidade das operações deste setor, defendem que um chef de cozinha é um profissional que possui muito mais do que um diploma de faculdade: deve possuir excelência técnica e saber comandar e gerenciar uma equipe composta por colaboradores com diferentes habilidades, limitações e personalidades. O termo chef designa, portanto, um cargo ocupado por um profissional capacitado e de ampla experiência e não o resultado de uma formação em si.

Seja o foco a formação de chefs ou não, para se aproximar das diretrizes legais, Miyazaki (2004) destaca a necessidade de os cursos de Gastronomia não se fixarem na formação de "reprodutores de receita", articulando conhecimentos de outras áreas. Para Domingues (2008), a formação em Gastronomia deve garantir não apenas o domínio de processos tecnológicos de gestão de produtos e serviços, mas, principalmente, a compreensão das relações humanas em diferentes espaços geográficos e socioculturais, contribuindo para a pesquisa e a disseminação da cultura e da ética. Para Hegarty (2011), é imprescindível que a formação superior habilite este aluno a aprender a aprender, se tornar empreendedor e inovador, sendo capaz de analisar criticamente as suas práticas.

Partindo de uma premissa semelhante, Schawn (2009) identificou 24 competências $^{5}$ fundamentais para chefs de cozinha em sua dissertação de mestrado e as classificou em 5 categorias, apresentadas no Quadro 1:

\begin{tabular}{|l|l|l|}
\hline & Categorias de competências & Descritivo \\
\hline 1 & Técnica & $\begin{array}{l}\text { Conhecer as normas de higiene e manipulação dos alimentos; conhecer } \\
\text { todas as funções a serem desenvolvidas pelos funcionários e preparações } \\
\text { culinárias da cozinha; saber técnicas culinárias e conservação dos } \\
\text { alimentos; conhecer os diversos tipos de ingredientes e sazonalidade; } \\
\text { identificar problemas no funcionamento da cozinha e procurar soluções; } \\
\text { usar a criatividade na produção de novos pratos. }\end{array}$ \\
\hline 2 & Administrativa & $\begin{array}{l}\text { Saber a missão e objetivos do restaurante; saber liderar; orientar e } \\
\text { supervisionar cozinheiros e auxiliares; coordenar, orientar e estabelecer } \\
\text { critérios de funcionamento e operação em todos os setores da cozinha; } \\
\text { planejar cardápio; controlar, orientar e disciplinar procedimentos em } \\
\text { relação ao manuseio de produtos e alimentos; solucionar problemas. }\end{array}$ \\
\hline
\end{tabular}

5 Uma competência, segundo Le Boterf (2003), é o resultado de três eixos: formação pessoal, formação educacional e experiência profissional. E não são apenas habilidades e conhecimentos conjugados, são habilidades e conhecimentos conjugados em ação (Fleury; Fleury, 2004). Já o termo habilidade pode ser definido como o saber-fazer necessário para a execução de determinada ação ou tarefa (Dutra, 2004). 


\begin{tabular}{|l|l|l|}
\hline 3 & Gestão de pessoal & $\begin{array}{l}\text { Estimular a equipe; ser autoritário; ser humilde; respeitar a equipe; aceitar } \\
\text { críticas; ser líder, educador e motivador; ser justo com a equipe; gerenciar } \\
\text { pessoas e conflitos. }\end{array}$ \\
\hline 4 & $\begin{array}{l}\text { Administração contábil- } \\
\text { financeira }\end{array}$ & Saber apurar os custos das preparações. \\
\hline 5 & Atendimento ao cliente & $\begin{array}{l}\text { Conhecer o perfil dos clientes que frequentam o restaurante; respeitar o } \\
\text { cliente. }\end{array}$ \\
\hline
\end{tabular}

Quadro 1. Categorias de competências de um chef de cozinha segundo Schawn (2009)

Fonte: A autora (2018), a partir de Schawn (2009).

Esta categorização evidencia a complexidade de formação de um chef e permite identificar alguns desafios, principalmente diante da duração dos cursos de, no máximo, quatro semestres. Por exemplo, ao analisar o currículo de três cursos de gastronomia do Estado de Santa Catarina, Domingues (2008) verificou que conteúdos referentes à gestão eram trabalhados superficialmente e constatou a ausência de conteúdos relacionados à geografia, história, sociologia, física e química e ao estímulo para a pesquisa. Ao estudar três cursos superiores ofertados no Estado de São Paulo, Abreu (2013) observou que as instituições apresentavam diferenças significativas em relação ao desenho do perfil do profissional, às metodologias adotadas e às disciplinas ofertadas. E embora a aproximação com o mercado de trabalho estivesse presente no discurso institucional, apenas uma Instituição de Ensino Superior (IES) oferecia oportunidades efetivas para que isso acontecesse. Também foi observada a necessidade de desenvolver práticas relacionadas à tomada de decisões e de soluções para problemas complexos, além do domínio de técnicas de cozinha.

Ao analisar o currículo e as estratégias educacionais de uma instituição de ensino superior em gastronomia na Nova Zelândia, Mitchell et al. (2013) observaram que mudanças no mercado da alimentação têm exigido uma nova abordagem em termos de formação, já que a formação tradicional não é mais suficiente para garantir o sucesso no mercado de trabalho. Contudo, a maioria das instituições ainda tende a oferecer uma formação centrada em técnicas tradicionais, baseada na gastronomia clássica francesa, mesmo que o mercado valorize iniciativas voltadas para a criatividade e a criação de novas experiências.

A proximidade com o mercado de trabalho é importante não apenas para que o aluno aprenda a reagir diante dos desafios que serão encontrados em seu cotidiano laboral, mas também para ajustar suas expectativas em relação à realidade do exercício profissional, notadamente no que se refere aos padrões de remuneração e às atividades que serão realizadas. Menciona-se, como exemplo, o trabalho de Werdini (2013), que comparou as expectativas dos alunos ingressantes e concluintes de cursos de gastronomia na cidade de São Paulo e identificou que, enquanto a grande maioria dos ingressantes acreditava que o mercado de trabalho estava aberto para a inserção dos formados, apenas metade dos concluintes assim indicaram. Da mesma forma, as expectativas em relação aos salários eram maiores entre os ingressantes do que entre os concluintes, e a perspectiva de trabalharem como empreendedores era maior entre os concluintes, já que os ingressantes se imaginavam trabalhando como chefs em restaurantes consagrados. O autor atribui este resultado à mitificação da gastronomia estimulada pela televisão e pela internet, cujos efeitos são mais fortes nos ingressantes, tendo em vista que os concluintes já possuem maior contato com a realidade do mercado. Sobre as expectativas dos alunos, Santos (2006, p.26), que estudou a formação empreendedora em cursos superiores em gastronomia, constata: 
Quando se formam, na maioria, os estudantes ficam frustrados, pois vão trabalhar em restaurantes comerciais, o que consideram muito pouco, já que estavam ávidos por trabalhar em restaurantes de alto nível, ou hotel 5 estrelas. Alguns buscam alternativas, como fazer cursos de Sommelier para trabalhos mais especializados, ou optam pelo próprio negócio, o próprio restaurante e não estão preparados para a gestão do seu negócio.

Esta distância entre as expectativas dos estudantes e as reais condições do mercado de trabalho é relatada em vários trabalhos, inclusive em publicações não acadêmicas. Por outro lado, do ponto de vista acadêmico, verifica-se uma lacuna em relação à percepção de profissionais em posição de contratação em relação à formação oferecida pelos cursos superiores.

\section{PROCEDIMENTOS METODOLÓGICOS}

Trata-se de uma pesquisa qualitativa, realizada por meio de uma pesquisa bibliográfica e documental (centrada em temas como formação superior e legislação pertinente) e pesquisa de campo (realizada a partir de uma survey). A pesquisa de campo possuiu duas iniciativas de coleta de dados desenvolvidas de forma simultânea: uma dedicada aos coordenadores de cursos superiores de Gastronomia do Estado de São Paulo, e outra dedicada aos profissionais em posição de contratantes, atuando no mesmo recorte geográfico.

O universo estudado foi delimitado a partir de um levantamento pelo sistema E-MEC ${ }^{6}$ para identificar quais cursos estavam ativos. A partir dos websites das IES, foram copiladas informações como as grades curriculares e o perfil do egresso de cada curso, as quais foram sistematizadas e sintetizadas e, ao serem confrontadas com os achados na literatura e no Parecer CNE/CES de 2006 e no CNCST (MEC, 2016), deram origem aos questionários aplicados na survey. Foi realizada ainda uma consulta à Plataforma de Currículos Lattes $^{7}$ para a caracterização da formação dos coordenadores.

Os questionários foram disponibilizados pela Plataforma SurveyMonkey. Pretendiase uma amostra censitária dos coordenadores, mas ao final foram registados 20 respondentes. Aos coordenadores foi garantido o anonimato, sendo solicitada a identificação da IES apenas para controle dos respondentes. A consulta aos profissionais possuiu caráter qualitativo e foi construída a partir da técnica de Snow Ball: alguns profissionais com o perfil adequado foram contatados inicialmente e a eles foi solicitada a indicação de outros profissionais, totalizando 152 respondentes válidos.

Os questionários foram compostos por perguntas abertas e fechadas. As perguntas fechadas foram tabuladas com recursos do SurveyMonkey; as perguntas abertas foram analisadas por meio de análise de conteúdo (Bardin, 2011) com categorização definida a posteriori: após a leitura e análise preliminar do material, os conteúdos foram organizados a partir de unidades de significação agrupadas por semelhança de forma a construir as

6 A Plataforma E-MEC (http://emec.mec.gov.br) é um sistema eletrônico criado com a função primordial de fazer a tramitação eletrônica de processos de regulamento da educação superior no Brasil, tanto no que se refere à atuação das IES e à autorização, como ao reconhecimento e à renovação de reconhecimento de cursos.

7 A Plataforma Lattes é vinculada ao CNPq (Conselho Nacional de Desenvolvimento Científico e Tecnológico) e consiste em um sistema de informações que reúne uma base de dados de currículos, de grupos de pesquisas e de instituições, criado com o objetivo de subsidiar as ações de planejamento, gestão e operacionalização dos fomentos do CNPq e de outras instituições federais e estaduais (CNPq, 2015). 
categorias de análise. Como muitas respostas abordaram diferentes aspectos, uma única contribuição pode conter mais de uma unidade de significado e corresponder a mais de uma categoria. As categorias mais recorrentes foram: (1) formação técnica (relacionada às práticas de cozinha, salão e segurança alimentar); (2) formação ampla (análise sensorial, comunicação, cultura gastronômica, gestão geral, gestão de recursos humanos, gestão financeira, marketing, idiomas, nutrição, pensamento crítico, pesquisa, primeiros socorros e sustentabilidade); (3) conduta profissional; (4) contato com o mercado de trabalho; (5) obtenção de diploma; (6) reconhecimento profissional; (7) remuneração.

\section{APRESENTAÇÃO E ANÁLISE DOS RESULTADOS}

Foram identificadas 44 IES ofertando cursos superiores de Gastronomia no Estado de São Paulo: 16 universidades, 15 centros universitários e 13 faculdades, nenhuma delas instituição pública. Ao todo, foram contabilizados 48 cursos: 3 tecnológicos na modalidade de Ensino a Distância (EAD), 2 bacharelados presenciais e 43 tecnológicos presenciais. Sobre a distribuição geográfica, 29 municípios possuíam cursos superiores em Gastronomia, com concentração de 12 cursos na capital.

A análise dos coordenadores considerou o perfil de 39 profissionais, já que não foi possível localizar o currículo ou identificar o nome de alguns. Destes, 19 possuem graduação tecnológica em Gastronomia (em 8 casos a Gastronomia é a segunda ou a terceira graduação), 7 são graduados em Nutrição e os 13 demais em outros cursos: Administração, Ciências Biológicas, Ciências Contábeis, Desenho Industrial, Direito, Educação Física, Farmácia, Hotelaria, Letras, Pedagogia, Processamento de Dados, Turismo e Relações Internacionais. A maioria dos coordenadores não possui formação em Gastronomia (20 coordenadores), mas já é expressivo o número dos formados na área. Em termos de pós-graduação, 3 possuem doutorado (em Farmacologia; Saúde Pública; e Ciências Biológicas), 21 possuem mestrado (as áreas com maior incidência são Hospitalidade, com 5; Educação, com 4; Ciências dos Alimentos, com 2); e 15 possuem especialização (as áreas com maior incidência são docência em nível superior, com 5; Gastronomia, com 4; e Eventos com 3).

\section{Visão dos CoORdenadores}

Os principais diferenciais proporcionados por uma graduação em Gastronomia indicados pelos Coordenadores são expressos no Quadro 2: 


\begin{tabular}{|c|c|c|}
\hline Categoria & Principais diferenciais proporcionados por uma graduação em Gastronomia & $\begin{array}{l}\text { № de } \\
\text { menções }\end{array}$ \\
\hline \multirow{7}{*}{$\begin{array}{l}\text { Formação } \\
\text { ampla }\end{array}$} & $\begin{array}{l}\text { Proporcionar uma formação ampla, que permita ao egresso atuar em diferentes } \\
\text { setores e empreendimentos da área de alimentação }\end{array}$ & 5 \\
\hline & $\begin{array}{l}\text { Proporcionar uma formação também voltada para o planejamento e para a } \\
\text { gestão de estabelecimentos de alimentação }\end{array}$ & 5 \\
\hline & Formar um profissional com pensamento crítico & 3 \\
\hline & $\begin{array}{l}\text { Proporcionar uma formação ampla que inclua temas relacionados à segurança } \\
\text { alimentar }\end{array}$ & 3 \\
\hline & $\begin{array}{l}\text { Proporcionar uma formação ampla que inclua temas relacionados à } \\
\text { sustentabilidade }\end{array}$ & 3 \\
\hline & $\begin{array}{l}\text { Formar um profissional que, além das habilidades técnicas, conheça a principal } \\
\text { bibliografia sobre a área e seja capaz de realizar pesquisas }\end{array}$ & 1 \\
\hline & Subtotal & 20 \\
\hline \multirow{3}{*}{$\begin{array}{l}\text { Formação } \\
\text { técnica }\end{array}$} & $\begin{array}{l}\text { Proporcionar uma formação técnica profissional sólida a partir de uma intensa } \\
\text { carga horária de aulas práticas }\end{array}$ & 15 \\
\hline & $\begin{array}{l}\text { Formar um profissional que possa exercitar sua criatividade a partir de um } \\
\text { grande repertório técnico }\end{array}$ & 2 \\
\hline & Subtotal & 17 \\
\hline \multirow{3}{*}{$\begin{array}{l}\text { Conduta } \\
\text { profissional }\end{array}$} & $\begin{array}{l}\text { Desenvolver uma conduta profissional e o comportamento ético no profissional } \\
\text { de cozinha }\end{array}$ & 4 \\
\hline & Formar um profissional com capacidade de adaptação & 3 \\
\hline & Subtotal & 7 \\
\hline \multirow{3}{*}{$\begin{array}{l}\text { Contato com } \\
\text { o mercado de } \\
\text { trabalho }\end{array}$} & $\begin{array}{l}\text { Proporcionar uma aproximação com o mercado de trabalho por meio da } \\
\text { participação em eventos e realização de estágios }\end{array}$ & 2 \\
\hline & $\begin{array}{l}\text { Proporcionar uma formação atualizada face às novas exigências e tendências do } \\
\text { mercado de alimentação }\end{array}$ & 2 \\
\hline & Subtotal & 4 \\
\hline \multirow[t]{2}{*}{$\begin{array}{l}\text { Obtenção do } \\
\text { diploma }\end{array}$} & $\begin{array}{l}\text { Ter uma formação superior em Gastronomia ainda é por si só um diferencial } \\
\text { para profissional }\end{array}$ & 2 \\
\hline & Subtotal & 2 \\
\hline \multicolumn{2}{|l|}{ Total } & 50 \\
\hline
\end{tabular}

Quadro 2. Principais diferenciais proporcionados por uma graduaçăo em Gastronomia na visăo dos coordenadores.

Fonte: A autora (2018).

A categoria de análise mais citada foi formação ampla, com destaque para conteúdos relacionados ao planejamento e à gestão de estabelecimentos, seguida pela categoria de formação técnica, relacionada à formação técnica em cozinha. A obtenção de um diploma de curso superior foi mencionada duas vezes. Desta forma, os principais diferenciais apontados pelos coordenadores foram a formação técnica em cozinha e a aquisição de uma formação ampla (que permite uma visão holística de um empreendimento de alimentos e bebidas), o que se alinha ao perfil descrito no CNCST (MEC, 2016). Considerando as competências indicadas por Schawn (2008), há correspondência com as categorias técnica e administrativa.

Os respondentes classificaram as atividades/ações consideradas fundamentais para a formação de um profissional em Gastronomia na seguinte ordem: (1) realizar uma graduação em Gastronomia; (2) realizar um estágio/trabalhar na área no Brasil; (3) realizar um estágio/trabalhar na área no exterior; (4) realizar cursos livres/de aperfeiçoamento no 
Brasil; (5) realizar um curso profissionalizante em uma instituição renomada no exterior; e (6) realizar cursos livres/de aperfeiçoamento no exterior. Como já era esperado, os respondentes valorizam a formação superior e entendem que a formação do aluno tem início na graduação e continuidade no mercado, inclusive por conta da curta duração dos cursos.

Sobre as habilidades e as competências necessárias para garantir a empregabilidade de um profissional na área de Gastronomia, foi solicitado aos coordenadores que indicassem, a partir de uma escala Likert de 5 pontos, o grau de importância atribuído a cada uma delas. Foram apresentadas 43 afirmações, distribuídas da seguinte forma pelas categorias analíticas: conduta profissional (9 afirmações), formação técnica (21 no total, sendo 17 afirmações para formação técnica em cozinha, 1 para formação técnica - cozinha/segurança alimentar e 3 afirmações para formação técnica salão), formação ampla (14 no total, sendo 8 afirmações para formação ampla - gestão, 2 para formação ampla - cultura gastronômica, 1 para formação ampla - comunicação, 1 para formação ampla - nutrição, 1 para formação ampla - pesquisa, 1 para formação ampla -segurança alimentar). O Quadro 3 apresenta as 10 habilidades e competências consideradas mais importantes pelos coordenadores.

\begin{tabular}{|l|l|l|}
\hline \multirow{2}{*}{ Categoria } & $\begin{array}{l}\text { Habilidades e competências consideradas mais importantes para garantir a } \\
\text { empregabilidade na área de Gastronomia }\end{array}$ & $\begin{array}{l}\text { Média } \\
\text { ponderada }\end{array}$ \\
\hline \multirow{4}{*}{$\begin{array}{l}\text { Conduta } \\
\text { profissional }\end{array}$} & Ser racional no uso de ingredientes e insumos & 5,00 \\
\cline { 2 - 3 } & Ser responsável, disciplinado e pontual & 5,00 \\
\cline { 2 - 3 } & Ser asseado e higiênico em relação à sua apresentação pessoal & 4,95 \\
\cline { 2 - 3 } & Saber trabalhar em equipe & 4,90 \\
\cline { 2 - 3 } & $\begin{array}{l}\text { Ser organizado em relação aos ingredientes, aos materiais e aos equipamentos } \\
\text { utilizados }\end{array}$ & 4,75 \\
\hline \multirow{4}{*}{$\begin{array}{l}\text { Fórmação } \\
\text { técnica }\end{array}$} & Dominar boas práticas de manipulação de alimentos & 4,80 \\
\cline { 2 - 3 } & Dominar diferentes técnicas de cocção & 4,75 \\
\cline { 2 - 3 } & Saber selecionar ingredientes & 4,65 \\
\cline { 2 - 3 } & Saber elaborar uma ficha técnica & 4,63 \\
\cline { 2 - 3 } & Saber elaborar um cardápio & 4,55 \\
\hline
\end{tabular}

Quadro 3. Dez habilidades e competências mais importantes para garantir a empregabilidade na área de Gastronomia na visão dos coordenadores.

Fonte: A autora (2018).

Duas categorias foram evidenciadas: conduta profissional e formação técnica. Notase que, em relação à conduta profissional, foram valorizados conteúdos que não pertencem a uma disciplina específica, mas são padrões de comportamentos ensinados e reforçados em diferentes disciplinas e que também dependem da personalidade do indivíduo.

Das habilidades e competências relacionadas à formação técnica - práticas de cozinha, verifica-se que 3 se referem aos procedimentos básicos (boas práticas de manipulação de alimentos, domínio de diferentes formas de cocção e saber selecionar ingredientes) e 2 exigem conhecimentos relacionados diretamente ao planejamento, organização e controle daquilo que é produzido pela cozinha: a elaboração de fichas técnicas (um instrumento de padronização de preparações e de controle de custos) e de cardápios (um instrumento de venda do que é produzido pelo estabelecimento). Considerando o proposto por Schawn (2008), há apenas correspondência com a categoria técnica. Em relação às 10 habilidades e às competências consideradas menos importantes, tem-se o Quadro 4: 


\begin{tabular}{|l|l|l|}
\hline \multirow{4}{*}{ Categoria } & $\begin{array}{l}\text { Habilidades e competências consideradas menos importantes para garantir a } \\
\text { empregabilidade na área de Gastronomia }\end{array}$ & $\begin{array}{l}\text { Média } \\
\text { ponderada }\end{array}$ \\
\hline \multirow{4}{*}{$\begin{array}{l}\text { Formação } \\
\text { ampla }\end{array}$} & $\begin{array}{l}\text { Ter conhecimentos sobre o gerenciamento geral de estabelecimentos de alimentos } \\
\text { e bebidas }\end{array}$ & 3,95 \\
\cline { 2 - 3 } & Ter conhecimentos sobre nutrição & 3,90 \\
\cline { 2 - 3 } & Ter conhecimentos sobre gestão de recursos humanos & 3,79 \\
\cline { 2 - 3 } & $\begin{array}{l}\text { Ter conhecimentos sobre o gerenciamento financeiro de estabelecimentos de } \\
\text { alimentos e bebidas }\end{array}$ & 3,75 \\
\cline { 2 - 3 } & Ter familiaridade com métodos e técnicas de pesquisa (acadêmica/de mercado) & 3,55 \\
\hline \multirow{4}{*}{$\begin{array}{l}\text { Formação } \\
\text { técnica }\end{array}$} & Dominar diferentes técnicas de panificação & 3,90 \\
\cline { 2 - 3 } & Ter conhecimentos sobre vinhos e suas harmonizações & 3,60 \\
\cline { 2 - 3 } & Ter conhecimentos sobre cervejas e suas harmonizações & 3,55 \\
\cline { 2 - 3 } & Ter conhecimentos sobre cafés e suas harmonizações & 3,40 \\
\hline $\begin{array}{l}\text { Conduta } \\
\text { profissional }\end{array}$ & Ter espírito empreendedor & 3,80 \\
\hline
\end{tabular}

Quadro 4. Dez habilidades e competèncias menos importantes para garantir a empregabilidade na área de Gastronomia na visão dos coordenadores

Fonte: A autora (2018).

A categoria formação ampla teve 5 menções entre os últimos colocados: 3 relacionadas à gestão (conhecimento do gerenciamento financeiro, de recursos humanos e gerenciamento geral de estabelecimentos de alimentos e bebidas), 1 relacionada à nutrição e 1 à pesquisa. A categoria formação técnica teve 4 menções: 3 para salão e 1 para cozinha, com destaque para habilidades relacionadas a carreiras (panificação, sommelier e barista) que exigem formação específica. Apenas a baixa importância atribuída aos itens "ter conhecimentos sobre o gerenciamento geral de estabelecimentos e bebidas" (34 ํㅜ posição) e "ter espírito empreendedor" (37a posição) não era esperada. Por outro lado, considerando os objetivos dos cursos tecnológicos, esperava-se que "pesquisa" não teria destaque nesta hierarquização.

Solicitou-se a indicação de habilidades ou competências essenciais não mencionadas. Houve 2 indicações para o atendimento e serviço de salão (categoria formação técnica - salão); 2 menções para desenvolver persistência, resiliência e capacidade de trabalhar sob pressão (categoria conduta profissional); 1 indicação para estar atento a questões de sustentabilidade (categoria formação ampla - sustentabilidade); 1 menção para desenvolver técnicas de relacionamento intra e interpessoal com empatia (categoria conduta profissional); e 1 indicação para desenvolver o desejo pela pesquisa e pelo aprendizado contínuo (que pertence às categorias conduta profissional e formação ampla).

A percepção dos coordenadores em relação à inserção dos egressos de cursos superiores em Gastronomia no mercado de trabalho em sua região de atuação é apresentada no Quadro 5.

\begin{tabular}{|l|l|l|}
\hline Categoria & A inserção dos egressos no mercado de trabalho segundo os coordenadores & $\begin{array}{l}\text { № de } \\
\text { menções }\end{array}$ \\
\hline \multirow{2}{*}{ Remuneração } & O mercado tem absorvido bem os egressos, mas os salários são baixos & 10 \\
\cline { 2 - 4 } & Subtotal & 10 \\
\hline
\end{tabular}




\begin{tabular}{|c|c|c|}
\hline \multirow{3}{*}{$\begin{array}{l}\text { Reconhecimento } \\
\text { do profissional }\end{array}$} & $\begin{array}{l}\text { A inserção ocorre, mas alguns empresários mais antigos ainda possuem } \\
\text { preconceito em relação aos egressos }\end{array}$ & 4 \\
\hline & $\begin{array}{l}\text { Há pouca valorização do profissional formado e isto dificulta a inserção no } \\
\text { mercado de trabalho }\end{array}$ & 1 \\
\hline & Subtotal & 5 \\
\hline \multirow{3}{*}{$\begin{array}{l}\text { Conduta } \\
\text { profissional }\end{array}$} & $\begin{array}{l}\text { Há boa inserção, mas a falta de conduta profissional de muitos resulta em } \\
\text { desemprego }\end{array}$ & 4 \\
\hline & $\begin{array}{l}\text { Há dificuldade de inserção porque nem todos os que fazem o curso têm perfil } \\
\text { para atuar em uma cozinha profissional }\end{array}$ & 1 \\
\hline & Subtotal & 5 \\
\hline \multirow[t]{2}{*}{ Carreira } & $\begin{array}{l}\text { A inserção ocorre, mas ocupações meramente operacionais tendem a frustrar } \\
\text { os egressos }\end{array}$ & 3 \\
\hline & Subtotal & 3 \\
\hline \multirow{2}{*}{$\begin{array}{l}\text { Ausência de } \\
\text { dificuldades }\end{array}$} & Há uma boa inserção e os alunos já terminam o curso empregados & 3 \\
\hline & Subtotal & 3 \\
\hline \multirow[t]{2}{*}{ Formação ampla } & $\begin{array}{l}\text { Há uma boa inserção, mas a falta de conhecimento mais aprofundado em } \\
\text { gestão de negócios pode atrapalhar }\end{array}$ & 1 \\
\hline & Subtotal & 3 \\
\hline \multicolumn{2}{|l|}{$\begin{array}{l}\text { Total } \\
\text { Quadro 5. Comen } \\
\text { coordenadores } \\
\text { Fonte: A autora (26 }\end{array}$} & 29 \\
\hline
\end{tabular}

Remuneração foi a categoria com o maior número de menções, com a indicação de que há boa absorção dos egressos, mas os salários baixos tendem a dificultar a permanência dos novos profissionais na área. As categorias reconhecimento profissional e conduta profissional receberam o mesmo número de indicações, todas com um sentido negativo, dificultando a inserção no mercado de trabalho. Para muitos respondentes há absorção dos egressos, mas as discrepâncias entre as expectativas dos alunos e a realidade do mercado, principalmente relacionadas à questão salarial (considerando o valor pago pela graduação) e às atividades que serão executadas, dificultam a sobrevivência no mercado de trabalho. Estas perspectivas se aproximam com as observações de Santos (2006), Belcufine (2011) e Werdini (2013).

Na categoria conduta profissional, identificaram-se também menções explícitas ao preconceito existente em relação aos egressos, muitas vezes considerados pouco humildes, pouco proativos e resistentes à disciplina, reforçando a ideia de que muitas vezes é o comportamento inadequado - e não a falta de perícia técnica - o que dificulta a absorção efetiva destes egressos. Os respondentes então apontaram as alterações necessárias nos currículos para aproximá-los do mercado de trabalho, conforme é apresentado no Quadro 6. 


\begin{tabular}{|c|c|c|}
\hline Categoria & Adequação ou alteração necessária nos currículos do curso de Gastronomia & $\begin{array}{l}\text { № de } \\
\text { menções }\end{array}$ \\
\hline \multirow{7}{*}{$\begin{array}{l}\text { Contato com } \\
\text { o mercado de } \\
\text { trabalho }\end{array}$} & Todos os cursos deveriam exigir estágio obrigatório & 6 \\
\hline & $\begin{array}{l}\text { Trabalhar conteúdos teóricos e práticos voltados para a realidade da região } \\
\text { onde o aluno estuda }\end{array}$ & 3 \\
\hline & $\begin{array}{l}\text { Flexibilizar o currículo para tratar de conteúdos mais dinâmicos e atuais, } \\
\text { relativos às tendências gastronômicas }\end{array}$ & 3 \\
\hline & $\begin{array}{l}\text { Melhorar o treinamento para a realidade do dia a dia de trabalho (longa } \\
\text { jornada de trabalho, ritmo de trabalho, ambiente de risco) }\end{array}$ & 2 \\
\hline & $\begin{array}{l}\text { Criar outras oportunidades de contato com o contexto profissional, além do } \\
\text { estágio }\end{array}$ & 2 \\
\hline & Criar e manter um restaurante escola real aberto ao público & 1 \\
\hline & Subtotal & 17 \\
\hline \multirow{5}{*}{ Formação ampla } & $\begin{array}{l}\text { Aumentar a carga horária relacionada à área de gestão de estabelecimentos e } \\
\text { empreendedorismo }\end{array}$ & 3 \\
\hline & Introduzir uma formação científica & 2 \\
\hline & Trabalhar ferramentas digitais de marketing & 2 \\
\hline & $\begin{array}{l}\text { Trabalhar questões de sustentabilidade em diferentes disciplinas ou em uma } \\
\text { disciplina específica }\end{array}$ & 1 \\
\hline & Subtotal & 8 \\
\hline \multirow{4}{*}{$\begin{array}{l}\text { Conduta } \\
\text { profissional }\end{array}$} & Incentivar mais o espírito crítico, a responsabilidade e a criatividade do aluno & 3 \\
\hline & $\begin{array}{l}\text { Criar uma cultura acadêmica que iniba comportamentos inadequados dos } \\
\text { alunos em relação à conduta profissional exigida pelo mercado }\end{array}$ & 2 \\
\hline & Enfatizar a necessidade de aprimoramento contínuo & 1 \\
\hline & Subtotal & 6 \\
\hline \multirow{3}{*}{ Formação técnica } & Aumentar a carga horária de aulas práticas de cozinha em alguns cursos & 3 \\
\hline & Melhorar a formação técnica relacionada à cozinha brasileira & 1 \\
\hline & Subtotal & 4 \\
\hline \multirow{2}{*}{$\begin{array}{l}\text { Alterações não } \\
\text { são necessárias }\end{array}$} & Nenhuma alteração precisa ser realizada & 4 \\
\hline & Subtotal & 4 \\
\hline \multirow[t]{2}{*}{ Órgão regulador } & $\begin{array}{l}\text { Criar um Conselho para regulamentar a profissão e estabelecer um piso } \\
\text { salarial }\end{array}$ & 2 \\
\hline & Subtotal & 2 \\
\hline \multirow{2}{*}{$\begin{array}{l}\text { Valorização do } \\
\text { docente }\end{array}$} & Valorizar mais o corpo docente & 2 \\
\hline & Subtotal & 2 \\
\hline \multirow{2}{*}{$\begin{array}{l}\text { Divulgação do } \\
\text { curso }\end{array}$} & $\begin{array}{l}\text { Divulgar melhor as características do curso e da carreira para evitar que alunos } \\
\text { sem o perfil para atuar na área se inscrevam }\end{array}$ & 2 \\
\hline & Subtotal & 2 \\
\hline \multirow{2}{*}{ Seleção de alunos } & Melhorar o processo seletivo dos alunos & 2 \\
\hline & Subtotal & 2 \\
\hline \multirow[t]{2}{*}{$\begin{array}{l}\text { Diretrizes } \\
\text { Curriculares }\end{array}$} & $\begin{array}{l}\text { Criar Diretrizes Curriculares para garantir as características gerais da formação } \\
\text { deste profissional }\end{array}$ & \\
\hline & Subtotal & 1 \\
\hline \multicolumn{2}{|l|}{ Total } & 48 \\
\hline
\end{tabular}

Quadro 6. Adequação ou alteraçäo necessária nos currículos do curso de Gastronomia na visäo dos coordenadores.

Fonte: A autora (2018). 
A categoria contato com o mercado de trabalho recebeu o maior número de menções, com destaque para a necessidade de adoção de estágio obrigatório (facultativo de acordo com a legislação vigente) em todos os cursos e a ampliação de conteúdos atuais e de relevância regional. Na sequência, a categoria formação ampla recebeu menções relacionadas à pesquisa, ao marketing e à sustentabilidade; seguida pela categoria conduta profissional, com ênfase em aspectos comportamentais. Quatro indicações mencionaram que alterações curriculares não eram necessárias e algumas sugestões escapam do escopo da matriz curricular e do projeto pedagógico, como a criação de um órgão regulador, a criação de diretrizes curriculares, a valorização do corpo docente e a melhoria das iniciativas de divulgação e seleção de alunos por parte das IES.

\section{VISÃO DOS PROFISSIONAIS DE MERCADO}

Entre os respondentes, constam 63 empresários, 40 chefs de cozinha, 26 consultores, 14 sous chefs, 7 gerentes e 2 sommeliers, que atuam em diferentes estabelecimentos ${ }^{8}$, o que ilustra a diversidade deste mercado de trabalho. Em relação à formação superior, apenas 14 respondentes não possuem. Daqueles com formação superior (138), 58,69\% (81) são formados em Gastronomia; 32,6\% (45) são formados em Gastronomia e em outro curso ${ }^{9} \mathrm{e}$ $8,69 \%$ (12) são formados em outros cursos $^{10}$.

Os profissionais respondentes classificaram as ações/atividades consideradas fundamentais para a formação de um profissional em Gastronomia, indicando: (1) realização de estágios e trabalhos na área no Brasil; (2) realização de um curso de graduação em Gastronomia; (3) realização de estágios e trabalhos na área no exterior, (4) realização de cursos livres e de aperfeiçoamento no Brasil; (5) realização de um curso profissionalizante no exterior. Embora as atividades profissionais sejam as mais valorizadas, destaca-se a indicação do curso superior em Gastronomia em segundo lugar um possível reflexo do número de respondentes que possuem esta formação.

Os diferenciais proporcionados por uma graduação em Gastronomia, na opinião dos profissionais do mercado, são apresentados no Quadro 7.

\begin{tabular}{|l|l|l|}
\hline \multirow{4}{*}{ Categoria } & Principais diferenciais proporcionados por uma graduação em Gastronomia & $\begin{array}{l}\text { № de } \\
\text { menções }\end{array}$ \\
\hline \multirow{5}{*}{$\begin{array}{l}\text { Formação } \\
\text { técnica }\end{array}$} & Ter conhecimento de técnicas e procedimentos profissionais & 28 \\
\cline { 2 - 3 } & Receber treinamento de técnicas e procedimentos profissionais & 12 \\
\cline { 2 - 3 } & Ter conhecimento amplo de diferentes tipos de cozinha, suas preparações e suas & 11 \\
\cline { 2 - 3 } & técnicas & 5 \\
\cline { 2 - 3 } & Ter conhecimento amplo sobre ingredientes & 4 \\
\cline { 2 - 3 } & Ter conhecimento sobre o planejamento de cardápios & 3 \\
\cline { 2 - 3 } & Ter conhecimento de técnimento de padrões superadas de cozinha & 2 \\
\cline { 2 - 3 } & Obter familiaridade com nomenclaturas e termos específicos de cozinha & 1 \\
\cline { 2 - 3 } & Subtotal & 66 \\
\hline
\end{tabular}

8 Os estabelecimentos mencionados foram restaurantes, empresas de eventos, empresas de consultoria, empresas de treinamento, bares, cafeterias, confeitarias, escola de culinária, delivery de congelados, pastifícios, produção e venda e produtos orgânicos, produtora culinária publicitária, indústria alimentícia, além de personal chefs.

9 Destes, 17 são formados em Gastronomia e Administração, 7 em Gastronomia e Nutrição, 5 em Gastronomia e Direito, 5 em Gastronomia e Letras, 4 em Gastronomia e Publicidade e Propaganda/Marketing, 3 em Gastronomia e Comunicação Social, 2 em Gastronomia e Pedagogia, 1 em Gastronomia e Artes Plásticas; e 1 em Gastronomia e Hotelaria.

10 Quatro respondentes (33,33\%) possuem graduação em Administração. Os demais cursos possuem apenas uma ocorrência: Administração e Publicidade e Propaganda; Comércio Exterior; Educação Física; Hotelaria; Letras e Desenho Industrial; Pedagogia; Psicologia; e Publicidade e Propaganda. 


\begin{tabular}{|c|c|c|}
\hline \multirow{7}{*}{$\begin{array}{l}\text { Formação } \\
\text { ampla }\end{array}$} & Ter conhecimento de história e cultura de alimentação & 8 \\
\hline & Ter conhecimento sobre gestão de pessoas & 8 \\
\hline & Ter conhecimento sobre gestão de um estabelecimento & 7 \\
\hline & Ter conhecimento sobre todos os setores de um restaurante & 6 \\
\hline & Ter conhecimento da legislação da ANVISA & 4 \\
\hline & $\begin{array}{l}\text { Ter conhecimento sobre o funcionamento de diferentes setores do mercado de } \\
\text { alimentos e bebidas }\end{array}$ & 3 \\
\hline & Subtotal & 36 \\
\hline \multirow{2}{*}{$\begin{array}{l}\text { Contato } \\
\text { com o } \\
\text { mercado de } \\
\text { trabalho }\end{array}$} & Estabelecer networking com professores e outros profissionais & 8 \\
\hline & Subtotal & 8 \\
\hline \multirow{3}{*}{$\begin{array}{l}\text { Conduta } \\
\text { profissional }\end{array}$} & Desenvolver uma conduta profissional & 5 \\
\hline & Habituar-se ao trabalho em equipe & 2 \\
\hline & Subtotal & 7 \\
\hline \multicolumn{2}{|l|}{ Total } & 117 \\
\hline
\end{tabular}

Quadro 7. Diferenciais proporcionados por uma graduaçáo em Gastronomia na visăo dos profissionais de mercado

Fonte: A autora (2018).

Em relação aos diferenciais, as categorias mais mencionadas foram: formação técnica - cozinha (66 menções), formação ampla (24 para gestão, 4 para cultura gastronômica e 4 para a segurança alimentar, totalizando 32 menções), aproximação com o mercado (8) e conduta profissional (7). Nota-se que o contato com os professores foi percebido como um diferencial. Foram identificadas críticas à conduta profissional de alguns egressos e mencionadas as dificuldades em reproduzir em sala de aula as reais condições de trabalho (como a pressão durante um serviço).

O Quadro 8 apresenta as dez habilidades e as competências consideradas mais importantes pelos profissionais respondentes para garantir a empregabilidade na área.

\begin{tabular}{|l|l|l|}
\hline \multirow{4}{*}{ Categoria } & $\begin{array}{l}\text { Habilidades e competências consideradas mais importantes para garantir a } \\
\text { empregabilidade na área de Gastronomia }\end{array}$ & $\begin{array}{l}\text { Média } \\
\text { ponderada }\end{array}$ \\
\hline \multirow{4}{*}{$\begin{array}{l}\text { Conduta } \\
\text { profissional }\end{array}$} & Ser asseado e higiênico em relação à sua apresentação pessoal & 4,82 \\
\cline { 2 - 4 } & $\begin{array}{l}\text { Ser responsável, disciplinado e pontual } \\
\text { utilizados }\end{array}$ & 4,80 \\
\cline { 2 - 4 } & Saber trabalhar em equipe & 4,71 \\
\cline { 2 - 4 } & Ser racional no uso de ingredientes e insumos & 4,71 \\
\hline \multirow{4}{*}{$\begin{array}{l}\text { Formação } \\
\text { técnica }\end{array}$} & Saber selecionar ingredientes & 4,53 \\
\cline { 2 - 4 } & Dominar boas práticas de manipulação de alimentos & 4,53 \\
\cline { 2 - 4 } & Dominar diferentes técnicas de cocção & 4,39 \\
\cline { 2 - 4 } & Saber elaborar uma ficha técnica & 4,38 \\
\hline $\begin{array}{l}\text { Formação } \\
\text { ampla }\end{array}$ & Saber gerenciar estoques & 4,29 \\
\hline
\end{tabular}

Quadro 8. Dez habilidađes e competências mais importantes para garantir a empregabitidade na área de Gastronomia na visão dos profissionais de mercado.

Fonte: A autora (2018) 
Observa-se a importância atribuída à categoria conduta profissional, com menções relacionadas às condutas básicas de higiene. Na sequência, aspectos comportamentais, como a responsabilidade, a pontualidade, o saber trabalhar em equipe e a organização foram destacados. Em relação à formação técnica, foram salientadas habilidades básicas (como selecionar ingredientes), havendo apenas uma referência às ações de planejamento e de gestão do que é produzido (elaborar ficha técnica). O Quadro 9 indica as habilidades e as competências consideradas menos importantes pelos profissionais consultados.

\begin{tabular}{|c|c|c|}
\hline Categoria & $\begin{array}{l}\text { Habilidades e competências consideradas menos importantes para } \\
\text { garantir a empregabilidade na área de Gastronomia }\end{array}$ & $\begin{array}{l}\text { Média } \\
\text { ponderada }\end{array}$ \\
\hline \multirow{5}{*}{ Formação técnica } & Dominar diferentes técnicas de pâtisserie & 3,48 \\
\hline & Dominar diferentes técnicas de panificação & 3,41 \\
\hline & Ter conhecimentos sobre vinhos e suas harmonizações & 3,12 \\
\hline & Ter conhecimentos sobre cervejas e suas harmonizações & 3,01 \\
\hline & Ter conhecimentos sobre cafés e suas harmonizações & 2,80 \\
\hline \multirow{4}{*}{ Formação ampla } & Ter conhecimentos sobre história e cultura da alimentação internacional & 3,43 \\
\hline & Ter conhecimentos sobre gestão de recursos humanos & 3,34 \\
\hline & Ter conhecimentos sobre nutrição & 3,32 \\
\hline & $\begin{array}{l}\text { Ter familiaridade com métodos e técnicas de pesquisa (acadêmica/de } \\
\text { mercado) }\end{array}$ & 3,01 \\
\hline Conduta profissional & Ter espírito empreendedor & 3,50 \\
\hline
\end{tabular}

A categoria formação técnica obteve 5 menções relacionadas às áreas de atuação panificação, pâtisserie, sommelier e barista, que demandam formações específicas. A categoria formação ampla recebeu 4 menções relacionadas à cultura gastronômica, à gestão de recursos humanos, aos conhecimentos de nutrição e à pesquisa. A categoria conduta profissional recebeu 1 menção, relacionada ao espírito empreendedor. A pouca relevância atribuída à pesquisa era esperada, mas a baixa relevância atribuída ao espírito empreendedor não.

Sobre as habilidades e as competências consideradas fundamentais que não constavam no questionário, a categoria mais mencionada foi formação ampla, com 31 indicações desdobradas em ensino de idiomas (10 menções), gestão (6 menções), análise sensorial (4 menções), recursos humanos (4 menções), marketing (3 menções), sustentabilidade (2 menções) e primeiros socorros (2 menções). A gestão de custos constava na listagem oferecida aos profissionais, mas mesmo assim foi mencionada.

O Quadro 10 apresenta os comentários dos profissionais sobre o ingresso dos formados no mercado de trabalho:

\begin{tabular}{|l|l|l|}
\hline Categoria & $\begin{array}{l}\text { A inserção dos egressos no mercado de trabalho segundo os profissionais } \\
\text { do mercado }\end{array}$ & $\begin{array}{l}\text { № de } \\
\text { menções }\end{array}$ \\
\hline \multirow{2}{*}{ Remuneração } & $\begin{array}{l}\text { Há inserção, mas os baixos salários dificultam a permanência no mercado } \\
\text { de trabalho }\end{array}$ & 38 \\
\cline { 2 - 3 } & Subtotal & 38 \\
\hline \multirow{2}{*}{$\begin{array}{l}\text { Obtenção de } \\
\text { diploma }\end{array}$} & $\begin{array}{l}\text { Há inserção, mas os egressos competem diretamente com pessoas que } \\
\text { não possuem formação superior na área, mas realizam um bom trabalho }\end{array}$ & 38 \\
\cline { 2 - 3 } & Subtotal & 38 \\
\hline
\end{tabular}




\begin{tabular}{|l|l|l|}
\hline \multirow{2}{*}{$\begin{array}{l}\text { Conduta } \\
\text { profissional }\end{array}$} & $\begin{array}{l}\text { Há inserção, mas a conduta profissional inadequada dificulta a } \\
\text { permanência no mercado de trabalho }\end{array}$ & 35 \\
\cline { 2 - 3 } & Subtotal & 35 \\
\hline \multirow{2}{*}{$\begin{array}{l}\text { Contato com } \\
\text { o mercado de } \\
\text { trabalho }\end{array}$} & $\begin{array}{l}\text { Há inserção, mas a falta de preparo para o ritmo e as condições de } \\
\text { trabalho em uma cozinha comercial dificultam a permanência no mercado } \\
\text { de trabalho }\end{array}$ & 25 \\
\cline { 2 - 3 } & Subtotal & 25 \\
\hline \multirow{2}{*}{ Carreira } & $\begin{array}{l}\text { Há inserção, mas as expectativas dos egressos em relação às tarefas que } \\
\text { deverão executar muitas vezes são equivocadas }\end{array}$ & 22 \\
\cline { 2 - 3 } & Subtotal & 22 \\
\hline \multirow{2}{*}{$\begin{array}{l}\text { Adaptação do } \\
\text { mercado }\end{array}$} & $\begin{array}{l}\text { Há inserção, mas o mercado ainda está se adaptando ao novo perfil de } \\
\text { profissionais }\end{array}$ & 8 \\
\cline { 2 - 3 } & Subtotal & 8 \\
\hline $\begin{array}{l}\text { Crise - } \\
\text { enxugamento de } \\
\text { equipes }\end{array}$ & $\begin{array}{l}\text { Há dificuldade de inserção por conta do enxugamento de equipes gerado } \\
\text { pela crise }\end{array}$ & 8 \\
\cline { 2 - 3 } & Subtotal & 8 \\
\hline \multirow{2}{*}{$\begin{array}{l}\text { Falta de } \\
\text { profissionalismo }\end{array}$} & $\begin{array}{l}\text { Há dificuldade de inserção por conta da falta de profissionalismo por } \\
\text { parte de muitos estabelecimentos }\end{array}$ & 2 \\
\cline { 2 - 3 } & Subtotal & 2 \\
\hline Total \\
$\begin{array}{ll}\text { Quadro 10. Comentários sobre a inserção e a permanência de egressos no mercado de trabalho na visão } \\
\text { dos profissionais de mercado } \\
\text { Fonte: A autora (2018) }\end{array}$ & 176 \\
\hline
\end{tabular}

As duas categorias mais mencionadas foram remuneração e obtenção do diploma, indicadas como dificuldades relacionadas à inserção. A primeira apontou que os baixos salários levam à desistência da carreira, a segunda indicou que os egressos competem com pessoas que não possuem formação na área, mas que realizam um bom trabalho (neste caso aspectos relacionados às habilidades práticas e à conduta profissional, como vontade de aprender e disciplina, foram destacados). Também foi observado que, com o aumento do número de formados em Gastronomia, ter um diploma não seria mais um diferencial.

As menções da categoria conduta profissional enfatizaram aspectos negativos, como a falta de pró-atividade, de comprometimento e de humildade; indisciplina; recusa em realizar tarefas básicas; e dificuldade em entender que o diploma não é sinônimo de sucesso, que é preciso trabalhar duro e perceber que há sempre muito a aprender. O termo preconceito foi mencionado, evidenciando que o mau comportamento de alguns pode interferir na percepção de todo um grupo. A categoria contato com o mercado remeteu à percepção de que muitas vezes o egresso tem conhecimento técnico, mas não consegue realizar as tarefas com a rapidez exigida em uma cozinha comercial. As menções relacionadas à categoria carreira, assim como as referentes à categoria remuneração, parecem ser fruto da distância entre as expectativas dos egressos e a realidade do mercado de trabalho. Esta perspectiva possui correlação com as observações feitas por Santos (2006), Belcufine (2011) e Werdini (2013).

Finalizando, os respondentes indicaram o que deveria ser ajustado nos currículos dos cursos superiores para aproximar a formação dos alunos às necessidades do mercado de trabalho. Esta pergunta originou respostas complexas, sintetizadas no Quadro 11: 


\begin{tabular}{|c|c|c|}
\hline Categoria & Adequação ou alteração necessária nos currículos do curso de Gastronomia & $\begin{array}{l}\text { № de } \\
\text { menções }\end{array}$ \\
\hline \multirow{8}{*}{$\begin{array}{l}\text { Contato com } \\
\text { o mercado de } \\
\text { trabalho }\end{array}$} & Ampliar a carga horária do estágio obrigatório & 34 \\
\hline & Treinar o aluno para a rotina e a realidade do mercado de trabalho & 32 \\
\hline & Melhorar a supervisão dos estagiários por parte do curso & 24 \\
\hline & Incluir o estágio obrigatório na grade curricular & 10 \\
\hline & Melhorar os conteúdos relacionados às realidades regionais & 8 \\
\hline & $\begin{array}{l}\text { Ampliar as possibilidades de estágio na área, incluindo outros } \\
\text { estabelecimentos, além de bares e restaurantes }\end{array}$ & 6 \\
\hline & Proporcionar treinamento dos alunos em um restaurante escola & 2 \\
\hline & Subtotal & 116 \\
\hline \multirow{13}{*}{ Formação técnica } & Melhorar o nível de cobrança técnica durante o curso & 30 \\
\hline & Melhorar o treinamento clássico & 8 \\
\hline & $\begin{array}{l}\text { Trabalhar mais conteúdos relacionados ao processo criativo de pratos e } \\
\text { cardápios }\end{array}$ & 7 \\
\hline & $\begin{array}{l}\text { Aumentar a carga horária geral do curso para aprofundar conteúdos das } \\
\text { disciplinas práticas }\end{array}$ & 6 \\
\hline & Trabalhar mais técnicas avançadas de cozinha & 4 \\
\hline & Ampliar a carga horária prática das disciplinas & 4 \\
\hline & Trabalhar melhor os conteúdos práticos relacionados à Gastronomia brasileira & 4 \\
\hline & Inserir no currículo disciplinas relacionadas ao serviço no salão & 4 \\
\hline & Trabalhar as disciplinas teóricas e práticas de forma mais integrada & 4 \\
\hline & Familiarização com equipamentos e utensílios associados à cozinha moderna & 3 \\
\hline & Melhorar o treinamento relacionado à cozinha moderna & 2 \\
\hline & Enfatizar técnicas relacionadas à diminuição de desperdício de ingredientes & 2 \\
\hline & Subtotal & 78 \\
\hline \multirow{11}{*}{ Formação ampla } & Aprofundar os conteúdos relacionados à gestão de restaurantes e similares & 14 \\
\hline & Apresentar as diferentes possibilidades de atuação na área de Gastronomia & 12 \\
\hline & Melhorar os conteúdos relacionados com a sustentabilidade & 10 \\
\hline & Melhorar os conteúdos associados ao empreendedorismo & 8 \\
\hline & $\begin{array}{l}\text { Aumentar a carga horária geral do curso para aprofundar conteúdos das } \\
\text { disciplinas teóricas }\end{array}$ & 6 \\
\hline & Aumentar a carga horária de disciplinas relacionadas à cultura gastronômica & 6 \\
\hline & Melhorar as habilidades de comunicação e expressão (inclusive escrita) & 4 \\
\hline & Trabalhar melhor os conteúdos teóricos relacionados à Gastronomia brasileira & 4 \\
\hline & $\begin{array}{l}\text { Estimular mais a pesquisa, tanto científica quanto a relacionada a ingredientes } \\
\text { e técnicas }\end{array}$ & 3 \\
\hline & Conduzir as disciplinas de gestão a partir da solução de problemas reais & 2 \\
\hline & Subtotal & 69 \\
\hline \multirow{3}{*}{$\begin{array}{l}\text { Conduta } \\
\text { profissional }\end{array}$} & $\begin{array}{l}\text { Enfatizar que uma carreira na cozinha precisa ser construída com muito } \\
\text { trabalho }\end{array}$ & 30 \\
\hline & Trabalhar melhor a conduta profissional (disciplina, postura, responsabilidade) & 30 \\
\hline & Subtotal & 60 \\
\hline \multicolumn{2}{|l|}{ Total } & 323 \\
\hline
\end{tabular}

Quadro 11. Adequaçoes ou alteraçoes necessárias aos cursos de graduação em Gastronomia na visão dos profissionais

Fonte: A autora (2018).

A categoria mais mencionada foi a de contato com o mercado de trabalho, com ênfase no estágio: a instituição de sua obrigatoriedade, a ampliação de sua carga horária e a melhoria da supervisão dos estagiários pelas IES foram recomendadas. A segunda categoria mais mencionada foi a de formação técnica, abordando a necessidade de melhorar o nível de exigência durante o curso, aperfeiçoar o treinamento de cozinha clássica e moderna, 
ampliar a carga horária das disciplinas, entre outras medidas. A categoria formação ampla foi associada à necessidade de ampliar a carga horária e melhorar os conteúdos relacionados à gestão, à sustentabilidade, ao empreendedorismo, à cultura gastronômica, à comunicação e expressão e à pesquisa. As menções da categoria conduta profissional, por sua vez, reforçam a necessidade de fazer com que os estudantes compreendam que a carreira na área exige dedicação e desenvolvam disciplina, postura e responsabilidade.

\section{ANÁLISE GERAL}

Em relação aos diferenciais oferecidos pela formação superior na área, observa-se que, a partir da análise dos quadros 2 e 7, os coordenadores indicaram a categoria formação ampla (com destaque para os conteúdos de gestão) em primeiro lugar e a categoria formação técnica (com conteúdos relacionados à cozinha), em segundo lugar; os profissionais do mercado destacaram a categoria formação técnica relacionada à cozinha em primeiro lugar e a categoria formação ampla, com ênfase nos conteúdos de gestão, em segundo. A categoria contato com o mercado de trabalho foi lembrada como um diferencial positivo pelos dois grupos de respondentes, mas a distância entre a formação oferecida e a realidade profissional foi recorrente nas respostas, principalmente na opinião dos profissionais do mercado.

Sobre a hierarquia atribuída às habilidades e às competências necessárias para garantir a empregabilidade na área, verifica-se uma forte congruência na visão dos dois grupos respondentes. Em relação às dez habilidades e às competências consideradas mais importantes, a partir da análise dos quadros 3 e 8, foi destacada a categoria conduta profissional (com 5 habilidades e competências coincidentes) e a categoria formação técnica associada à cozinha (com 4 habilidades e competências coincidentes). As discrepâncias de opinião dizem respeito a saber elaborar um cardápio (formação técnica - cozinha) indicada na $10^{\underline{a}}$ posição pelos coordenadores e na $11^{\text {a }}$ posição pelos profissionais; e saber gerenciar estoques (formação ampla), indicada na $24^{a}$ posição pelos coordenadores e na $10^{a}$ posição pelos profissionais. Há ainda fortes similaridades entre as habilidades e as competências consideradas menos importantes: entre as dez citações, há sete coincidentes, com destaque para formação ampla associada à gestão de recursos humanos, conteúdos de nutrição e formação nas áreas de panificação, sommelier de vinhos, sommelier de cervejas e barista.

Ao indicar as habilidades e as competências que não haviam sido contempladas pelo questionário, mas que são consideradas fundamentais, os coordenadores privilegiaram conteúdos relacionados à categoria conduta profissional. Houve apenas 1 menção à categoria formação ampla, relacionada aos conteúdos sobre sustentabilidade. Os profissionais, por sua vez, apontaram habilidades e competências pertencentes principalmente à formação ampla, enfatizando a aprendizagem de idiomas.

Sobre a inserção dos egressos no mercado de trabalho, a partir da análise dos quadros 5 e 9, verifica-se que tanto coordenadores quanto profissionais acreditam que ela ocorra. Os baixos salários e as ocupações pouco criativas são mencionados com as principais dificuldades para a permanência na área, assim como a falta de conduta profissional de alguns egressos. A competição entre egressos e pessoas sem formação superior na área foi destacada principalmente pelos profissionais de mercado. O termo 'preconceito' foi mencionado como resultado da mentalidade de empresários mais antigos 
e da má experiência destes com egressos pouco comprometidos ou mal preparados para as exigências da realidade profissional. Os dois grupos concordaram que egressos com boa formação técnica, interessados em aprender, dotados de disciplina e cientes do esforço necessário para construir uma carreira de sucesso, têm boa inserção no mercado de trabalho.

No que se refere aos ajustes necessários nos currículos, com base nos quadros 6 e 10, verifica-se que o principal ponto de convergência entre os dois grupos residiu na preocupação em aumentar o contato do formando com a realidade profissional, com destaque para o estágio. Torná-lo obrigatório, ampliar sua carga horária e melhorar a supervisão do aluno (esta última medida indicada apenas por profissionais do mercado) foram algumas das recomendações. A necessidade de ampliar o contato com o mercado de trabalho foi justificada por diferentes motivos: tornar conhecidas as rotinas e as exigências de um restaurante ou similar (em termos de ritmo de execução de tarefas, padrões de execução diante da exigência de clientes reais, disciplina e organização necessárias) e ajustar as expectativas dos alunos em relação à remuneração, às atividades que serão desempenhadas e às possibilidades de ascensão na carreira. Nota-se que a discrepância entre as expectativas dos estudantes e a realidade do mercado de trabalho também é mencionada nas pesquisas de Schawn (2009), Toledo (2010), Belcufini (2011) e Werdini (2013), sendo sempre associada, nestes trabalhos, à glamourização midiática da figura do chef.

Sobre os ajustes curriculares necessários, a categoria formação ampla, relacionada à gestão, foi destacada por coordenadores e profissionais; enquanto a formação técnicacozinha foi destacada principalmente pelos profissionais, que muitas vezes usaram o verbo 'treinar' ao tratar do tema. Apenas entre os coordenadores foram apontados aspectos que fogem do escopo curricular, tais como a necessidade de criação de um Conselho Profissional e da regulamentação da profissão ${ }^{11}$, ainda não consolidada.

\section{CONSIDERAÇÕES FINAIS}

O crescimento da oferta de ensino superior na área de Gastronomia, a compreensão da natureza desta formação e a inserção deste novo perfil profissional no mercado de trabalho são temas instigantes que suscitam diferentes análises. Esta pesquisa verificou que coordenadores e profissionais do mercado convergem em muitas opiniões, tendo os coordenadores uma postura mais evidente de defesa dos cursos superiores; e os profissionais do mercado de maior crítica à formação fornecida. Destaca-se, por parte dos profissionais, a insatisfação em relação à postura pouco profissional dos egressos e uma preocupação para que questões vinculadas à conduta profissional sejam enfatizadas pelos cursos superiores, mesmo que estas não sejam objeto de uma disciplina específica.

As falsas expectativas dos alunos em relação à remuneração, ao cotidiano criativo e à rápida ascensão na carreira foram uma constante nas respostas dos dois grupos. Há comentários de que mesmo que a formação técnica oferecida seja adequada, ela não é próxima da realidade (há menções, por parte dos profissionais, que falta 'ritmo' aos recém-

11 Nos últimos anos, identificaram-se duas tentativas de regulamentação de profissões relacionadas à Gastronomia. O Projeto de Lei da Câmara dos Deputados 74/2011, que trata da regulamentação da profissão de cozinheiro, foi rejeitado em caráter terminativo em 14/07/2017 (Câmara dos Deputados, 2017a). O Projeto de Lei da Câmara dos Deputados 2079/2011, que trata da regulamentação da profissão de gastrólogo, continua em tramitação, tendo sido a denominação profissional alterada de gastrólogo para gastrônomo (Câmara dos Deputados, 2017b). 
formados). A avaliação geral é a de que a inserção dos formados no mercado de trabalho ocorre de forma positiva, porém a baixa remuneração e a rotina desgastante com atividades operacionais repetitivas tendem a fazer com que muitos profissionais desistam precocemente de suas carreiras.

A formação acadêmica e a formação prática são vistas como complementares; a formação ampla, com destaque para os conteúdos de gestão, foi indicada como o principal diferencial oferecido pelos cursos superiores pelos coordenadores, enquanto os profissionais do mercado apontaram a formação técnica em cozinha como o principal diferencial, o que indica que os conteúdos relacionados à gestão de estabelecimentos talvez não sejam suficientes ou totalmente ajustados à realidade do mercado. O contato com o mercado de trabalho possibilitado durante o curso é percebido pelos dois grupos de respondentes ao mesmo tempo como um diferencial e um elemento que precisa ser ajustado, para garantir uma formação de qualidade para os estudantes.

As principais contribuições deste artigo dizem respeito aos dados empíricos coletados junto a dois grupos fundamentais para a formação e a inserção dos egressos no mercado de trabalho: os coordenadores de curso, que concebem e coordenam as ações pedagógicas que são oferecidas aos alunos; e os profissionais em posição de contratação, que selecionam e recebem estes egressos no ambiente profissional. Indica-se como limitações deste estudo a impossibilidade de comparar os dados empíricos coletados com os dados constantes nos projetos pedagógicos, bem como o fato de apenas 20 coordenadores terem respondido. A amostra dos profissionais apresentou uma concentração geográfica na capital, e outras iniciativas semelhantes poderiam buscar garantir uma maior dispersão geográfica.

Contudo, acredita-se que os resultados aqui apresentados, na medida em que apresentam e comparam as perspectivas de coordenadores e profissionais, podem suscitar reflexões sobre as especificidades da formação superior em Gastronomia no Estado de São Paulo, principalmente sob a perspectiva de quem concebe e coordena tais cursos, de forma a melhorar as relações entre o mercado e a academia.

\section{REFERÊNCIAS}

Abreu, L. M. (2013) O espaço curricular em cursos tecnológicos em Gastronomia: uma análise de três instituições no Estado de São Paulo sob a perspectiva de seus atores. Programa de PósGraduação em Hospitalidade (Dissertação de Mestrado), São Paulo.

Anjos, F., Cabral, S. R., \& Hostins, R. C. L. (2017). O cenário da formação superior em gastronomia no Brasil: uma reflexão da oferta. Revista Hospitalidade. São Paulo, 14(1), p.1-21.

Atala, A. \& Dória, C. A. (2008) Com unhas, dentes \& cuca: prática culinária e papo cabeça ao alcance de todos. São Paulo: Senac.

Bardin, L. (2011) Análise de conteúdo. Versão ampliada e revisada. São Paulo: Edições 70.

Belculfine, M. N. (2011) Tecnologia em Gastronomia: um estudo exploratório dos cursos segundo seus atores. Programa de Pós-Graduação (Mestrado) em Hospitalidade. Universidade Anhembi Morumbi, São Paulo. 110p. 
Câmara dos Deputados. (2017a). PL 2079/2011. Disponível em: http://www.camara.gov.br/ proposicoesWeb/fichadetramitacao?idProposicao=516781 Recuperado em 10.out.2017.

Câmara dos Deputados. (2017b). Comissão do Trabalho aprova regulamentação da gastronomia. Disponível em: http://www2.camara.leg.br/camaranoticias/noticias/TRABALHOE-PREVIDENCIA/494739-COMISSAO-DE-TRABALHO-APROVA-REGULAMENTACAO-DAGASTRONOMIA.html Recuperado em: 10.out.2017.

Carneiro, A. (2008) A formação acadêmico-profissional para inclusão social nos cursos superiores de turismo: dos aspectos socioeconômicos à discussão curricular. Programa de Pós-Graduação (Doutorado) em Educação. Pontifícia Universidade Católica de São Paulo, São Paulo, 201 p.

CNPQ (2017) Plataforma Lattes. Disponível em: http://lattes.cnpq.br/ Recuperado em 10.ago.2017.

Croce, E. \& Perri, G. (2010) Food and wine tourism. Cambridge: CABI.

Domingues, J. (2008) Formação em Gastronomia: ingredientes e temperos de um profissional. Programa de Pós-Graduação (Mestrado) em Turismo e Hotelaria. Universidade do Vale do Itajaí, Balneário Camboriú. 160p.

Dutra, J. (2004) Competências: conceitos e instrumentos para a gestão de pessoas na empresa moderna. São Paulo: Atlas.

Fleury, A. \& Fleury, M. T. L. (2004) Alinhando estratégia e competências. Revista de Administração de Empresa. Rio de Janeiro, 44 (1), 44-57.

Gimenes-Minasse, M. H. S. G. (2015) A formação superior em gastronomia: análise descritiva das dissertações de mestrado produzidas no Brasil até 2012. Revista Brasileira de Pesquisa em Turismo. São Paulo, 9(1), 156-173.

Hegarty, J. (2011) Achieving excellence by means of critical reflection and cultural imagination in culinary arts and gastronomy education. Journal of Culinary Science and Technology, 9(2), 55-65.

Hertzman, J. \& Ackerman, R. (2010) Evaluating quality in associate culinary arts programs. Quality assurance in education, 18(3), 209-226.

Krause, R. W. (2001) Educação superior em Gastronomia no Brasil: da necessidade ao projeto pedagógico do curso da Univali, Dissertação (Mestrado em Turismo e Hotelaria), Universidade do Vale do Itajaí, Balneário Camboriú, 131p.

Le Boterf, G. (2003) Desenvolvendo a competência dos profissionais. 3. ed. Porto Alegre: Artmed.

Lima, T. (2010) Formação profissional em Gastronomia: um estudo com os chefes de cozinha na cidade de João Pessoa (PB). Programa de Pós-Graduação (Mestrado) em Hospitalidade. Universidade Anhembi Morumbi, São Paulo, 111p.

MEC (2016) Catálogo nacional dos cursos superiores de tecnologia. Disponível em: http:// portaldoprofessor.mec.gov.br/storage/materiais/0000009402.PDF . Acesso em 10.abr. 2017.

MEC (2017) Listagem dos cursos superiores em Gastronomia - instituições de ensino superior credenciadas no MEC. Sistema E-MEC. Disponível em: http://emec.mec.gov.br/ Recuperado em: 25.jul.2017.

Mitchell, R., Woodhouse, A., \& Heptinstall, T., Camp, J. (2013). Why use design methodology in 
culinary arts education? Hospitality and society, 3(3), p.239-260.

MTE. (2010) Cadastro Brasileiro de ocupações. Disponível em: http://www3.mte.gov.br/pdet/ajuda/ notas_comunic/comu16510.asp Recuperado em: 05.abr.2017.

Miyazaki, M. (2006) Ensinando e aprendendo Gastronomia: percursos de formação de professores. Programa de Pós-Graduação (Mestrado) em Educação. Universidade Metodista de Piracicaba, Piracicaba, 115p.

Rampim, B. (2010) Entre panelas, livros e tradições: as trajetórias de formação do professor de gastronomia. Programa de Pós-Graduação (Mestrado) em Educação. Universidade Nove de Julho, São Paulo, 223p.

Richards, G. (2002) Gastronomy: an essential ingredient in tourism production and consumption? In: Hjalager, A.-M.; Richards, G. (org). Tourism and gastronomy. New York: Routledge, p.3-20.

Rubim, R. \& Rejowski, M. (2013) O ensino superior da Gastronomia no Brasil: análise da regulamentação, da distribuição e do perfil geral da formação (2010-2012). Revista Turismo Visão e Ação, 5(2),166-184.

Santich, B. (2004) The study of gastronomy and its relevance to hospitality education and training. Hospitality Management. 23(1), p.5-24.

Santos, A. (2006) A formação empreendedora em gastronomia: desafios para futuros gestores. Programa de Pós-Graduação (Mestrado) Profissional em Administração. Universidade Metodista de Piracicaba, Piracicaba, 86p.

Schluter, R. (2006) Turismo y património gastronómico. Buenos Aires: CIET.

Schwan, T. (2009) As competências do chef de cozinha. Programa de Pós-Graduação (Mestrado) em Hospitalidade. Universidade Anhembi Morumbi, São Paulo. 97p.

Toledo, R. F. M. \& Bergamo, M. (2011). O currículo gastronômico: um universo a ser explorado. Tomimatsu, C. E.; Furtado, S. M. (orgs). Formação em Gastronomia. Boccato: São Paulo, p.72-86.

Werdini, M. (2013) Formação superior em Gastronomia na cidade de São Paulo: expectativa e satisfação de alunos de uma instituição privada. Programa de Pós-Graduação (Mestrado) em Hospitalidade. Universidade Anhembi-Morumbi, São Paulo. 113p.

Contribuições de cada autor:

Maria Henriqueta S. G. Gimenes-Minasse: Estruturação da pesquisa, coleta e análise de dados, redação final e revisão do artigo. 